\title{
Author Correction: Inhibition of hypoxia-inducible factor-2 $\alpha$ in renal cell carcinoma with belzutifan: a phase 1 trial and biomarker analysis
}

Toni K. Choueiri (D), Todd M. Bauer, Kyriakos P. Papadopoulos, Elizabeth R. Plimack (D), Jaime R. Merchan, David F. McDermott (D, M. Dror Michaelson (D), Leonard J. Appleman, Sanjay Thamake, Rodolfo F. Perini, Naseem J. Zojwalla and Eric Jonasch (iD

Correction to: Nature Medicine https://doi.org/10.1038/s41591-021-01324-7, published online 22 April 2021

In the version of this Letter initially published, the Acknowledgements section omitted the following text: "T.K.C. is supported in part by the Dana-Farber/Harvard Cancer Center Kidney Specialized Program of Research Excellence and program, the Kohlberg Chair at Harvard Medical School, the Trust Family, Michael Brigham, and Loker Pinard Funds for Kidney Cancer Research at Dana-Farber Cancer Institute, and by various grants from the National Cancer Institute, Department of Defense, and foundations. Authors were also supported by NCI grants P50 CA101942 and U01 CA236489 to D.F.M. and T.K.C." This addition has now been included in the Acknowledgements.

The original Letter has been corrected in the online version of the paper.

Published online: 27 August 2021

https://doi.org/10.1038/s41591-021-01516-1

(c) The Author(s), under exclusive licence to Springer Nature America, Inc. 2021

\section{Author Correction: Pan-viral serology implicates enteroviruses in acute flaccid myelitis}

Ryan D. Schubert (D, Isobel A. Hawes, Prashanth S. Ramachandran, Akshaya Ramesh, Emily D. Crawford, John E. Pak, Wesley Wu, Carly K. Cheung, Brian D. O'Donovan, Cristina M. Tato, Amy Lyden, Michelle Tan, Rene Sit, Gavin M. Sowa, Hannah A. Sample, Kelsey C. Zorn (1D, Debarko Banerji, Lillian M. Khan, Riley Bove, Stephen L. Hauser, Amy A. Gelfand, Bethany L. Johnson-Kerner, Kendall Nash, Kalpathy S. Krishnamoorthy, Tanuja Chitnis, Joy Z. Ding, Hugh J. McMillan, Charles Y. Chiu (1), Benjamin Briggs, Carol A. Glaser, Cynthia Yen, Victoria Chu (D), Debra A. Wadford,

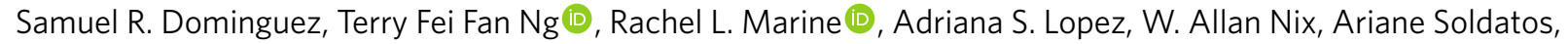
Mark P. Gorman, Leslie Benson, Kevin Messacar, Jennifer L. Konopka-Anstadt (D), M. Steven Oberste, Joseph L. DeRisi and Michael R. Wilson (1)

Correction to: Nature Medicine https://doi.org/10.1038/s41591-019-0613-1, published online 21 October 2019.

In the version of this article initially published, a middle initial for one author name (Gavin A. Sowa) was incorrect. The correct name is 'Gavin M. Sowa'. The error has been corrected in the HTML and PDF versions of the article.

Published online: 21 September 2021

https://doi.org/10.1038/s41591-021-01429-Z

This is a U.S. government work and not under copyright protection in the U.S.; foreign copyright protection may apply 2021 